\title{
Addition of interleukin- 6 to mouse embryo culture increases blastocyst cell number and influences the inner cell mass to trophectoderm ratio
}

\author{
Rebecca L Kelley, David K Gardner \\ School of Biosciences, University of Melbourne, Parkville, Australia
}

Objective: In vitro culture of preimplantation embryos is improved by grouping embryos together in a drop of media. Individually cultured embryos are deprived of paracrine factors; with this in mind, we investigated whether the addition of a single embryo-secreted factor, interleukin-6 (IL-6), could improve the development of individually cultured embryos.

Methods: Mouse embryos were cultured individually in $2 \mu \mathrm{L}$ of G1/G2 media in $5 \%$ oxygen and supplemented with a range of doses of recombinant mouse or human IL-6.

Results: Mouse IL-6 increased hatching at doses of 0.01 and $10 \mathrm{ng} / \mathrm{mL}$ compared to the control (93\% and $93 \% \mathrm{vs.} 78 \%, p<0.05)$ and increased the total number of cells at a dose of $0.1 \mathrm{ng} / \mathrm{mL}$ compared to the control $(101.95 \pm 3.36 \mathrm{vs} .91 .31 \pm 3.33, p<0.05)$. In contrast, the highest dose of $100 \mathrm{ng} / \mathrm{mL}$ reduced the total number of cells $(79.86 \pm 3.29, p<0.05)$. Supplementation with human IL-6 had a different effect, with no change in hatching or total cell numbers, but an increase in the percentage of inner cell mass per embryo at doses of $0.1,1$, and $100 \mathrm{ng} / \mathrm{mL}$ compared to the control $(22.9 \% \pm 1.1 \%, 23.3 \% \pm 1.1 \%$, and $23.1 \% \pm 1.1 \%$ vs. $19.5 \% \pm 1.0 \%, p<0.05)$.

Conclusion: These data show that IL-6 improved mouse embryo development when cultured individually in complex media; however, an excess of IL-6 may be detrimental. Additionally, these data indicate that there is some cross-species benefit of human IL-6 for mouse embryos, but possibly through a different mechanism than for mouse IL-6.

Keywords: Culture media; Cytokines; Embryology; Fertilization in vitro; Mice; Preimplantation

\section{Introduction}

In vitro fertilization (IVF) clinics routinely culture preimplantation embryos in vitro, but the techniques and conditions used by different clinics can vary widely [1]. The environment that embryos are exposed to can influence not only preimplantation development, but

Received: Jan 23, 2017· Revised: May 17, 2017 · Accepted: Jun 19, 2017 Corresponding author: David K Gardner

School of Biosciences, University of Melbourne, Royal Parade, Parkville, Victoria 3010, Australia

Tel: +61-3-8344-4345 Fax:+61-3-8344-7854

E-mail: david.gardner@unimelb.edu.au

*This work was funded by the University of Melbourne.

This is an Open Access article distributed under the terms of the Creative Commons Attribution Non-Commercial License (http://creativecommons.org/licenses/by-nc/4.0/) which permits unrestricted non-commercial use, distribution, and reproduction in any medium, provided the original work is properly cited. also implantation potential, fetal and placental development, and even adult health [2]. In vitro, embryos can be cultured individually or in groups within the same drop or well of media. Grouping embryos results in faster cleavage times, higher blastocyst and hatching rates, and more cells per blastocyst [3-9]. It is plausible that the impaired development of individually cultured embryos is due, at least in part, to being deprived of paracrine signaling molecules [5]. In vivo, these are produced by the oviduct and endometrium, and in vitro by neighboring embryos. Culturing individual mouse or bovine embryos in embryo-conditioned media increases the hatching rates and cell numbers to the same level as grouped embryos [9-11], but the composition of embryo-conditioned media is ill-defined and the roles of the components in signaling are largely unknown $[12,13]$. One of these embryo-secreted molecules found in conditioned media is the cytokine interleukin-6 (IL-6) [14-17]. 
IL-6 is a cytokine with many roles in cell signaling and a wide range of target genes [18]. Both IL-6 and its receptor are expressed and secreted in the endometrium in multiple species, including humans [19-23], and expression of the IL-6 receptor (IL-6R) has been identified in preimplantation murine embryos [24], indicating that preimplantation embryos are exposed to and can respond to IL-6 in vivo. Several studies have also observed the secretion of IL- 6 by preimplantation embryos [14-17], and in a multiplex assay of mouse embryo-conditioned media we found that IL-6 was the most abundant of the selected cytokines and growth factors in embryo-conditioned G2 media (Kelley, Hannan and Gardner, unpublished observations). Shen et al. [25] supplemented mouse embryo culture media with recombinant mouse IL-6 (rmlL-6) and found an increase in blastocyst cell numbers, as well as changes in signal transducer and activator of transcription 3 (STAT3) and the expression of anti-apoptotic genes. However, the culture conditions used by Shen et al. were designed to place the embryos under high stress, and therefore are not a reflection of current clinical practice for embryo culture. Some growth factors and cytokines are only effective in promoting embryo growth when culture conditions are suboptimal [26,27]; therefore, the aim of this study was to determine whether IL- 6 would promote the growth of individually cultured mouse embryos under more optimized culture conditions.

Culture of bovine or feline embryos with mouse embryos can stimulate development $[28,29]$, but little is known about the cross-species effects of specific components of the embryo secretome. Human IL-6 has only $42 \%$ amino acid sequence homology with mouse IL-6 [30], and has less affinity for the murine receptor IL-6R [31], which is expressed at the blastocyst stage [24]. Shen et al. [32] found that mouse IL- 6 had no effect on porcine parthenote embryos, but the response of mouse embryos to human IL- 6 is unknown. Thus, this study compared the effect of mouse and human IL-6 on mouse embryos.

\section{Methods}

\section{Animals}

C57BL/6 X CBA F1 hybrid mice were housed in a standard animal research facility in individually ventilated cages (Optimice; Animal Care Systems, Centennial, CO, USA) with a 12-hour light-dark photoperiod (6 AM-6 PM) and controlled temperature. Food and water were available ad libitum.

Four-week-old females were superovulated with $5 \mathrm{IU}$ of pregnant mare serum gonadotropin (Folligon; Intervet, Bendigo East, Australia) administered intraperitoneally at the mid-point of the light phase, followed 48 hours later by 5 IU of human chorionic gonadotropin (hCG) (Chorulon, Intervet) and mating with males of the same strain overnight. Mice were killed by cervical dislocation. All experiments were approved by The University of Melbourne Animal Ethics Committee (ID: 1413159.2).

\section{Embryo culture}

Pronucleate oocytes were collected 22 hours after hCG injection in G-MOPS PLUS handling medium containing $5 \mathrm{mg} / \mathrm{mL}$ of human serum albumin (HSA; Vitrolife, Gothenburg, Sweden), as described previously [33,34]. Embryos were incubated in G-MOPS PLUS containing $550 \mathrm{IU} / \mathrm{mL}$ of hyaluronidase (bovine testes type IV-S) until the cumulus cells were removed, then washed three times in G-MOPS PLUS and once in preincubated G1 culture medium. Embryos were pooled and allocated randomly to treatments and cultured in G1 medium for 48 hours, and then in G2 medium for a further 48 hours. When media were changed, embryos were washed once in $\mathrm{G} 2$ before they were moved to the culture drop. All embryo manipulations were performed on a SMZ 1500 microscope with a heated stage (Nikon Instruments, Melville, NY, USA). Embryo development was assessed on the morning of days 3,4 , and 5 of culture (70, 94 and 118 hours posthCG). Developmental stages were defined as follows: "compacting," the loss of membrane definition between blastomeres; "early blastocyst," the presence of a blastocoel cavity less than half the volume of the embryo; "blastocyst," the presence of a cavity occupying at least half the volume of the embryo; "expanded," increased volume of the blastocyst and thinning of the zona; "hatching," the appearance of cells outside the zona; "fully hatched," the complete evacuation of the embryo from the zona [34].

Embryo cultures were performed in $35 \mathrm{~mm}$ petri dishes (Falcon Easy-Grip; Corning Life Sciences, Tewksbury, MA, USA) under paraffin oil (Ovoil, Vitrolife) in a humidified multi-gas incubator at $37^{\circ} \mathrm{C}$ (MCO$5 \mathrm{M}$; Sanyo Electric, Osaka, Japan) in a reduced oxygen environment $\left(5 \% \mathrm{O}_{2}, 6 \% \mathrm{CO}_{2}\right.$, and $\left.89 \% \mathrm{~N}_{2}\right)$. Single embryos were cultured in $2 \mu \mathrm{L}$ of medium in $5 \%$ oxygen.

Culture media were prepared as described previously [33,34], except that choline chloride, folic acid, inositol, nicotinamide, and taurine were omitted from $\mathrm{G} 2$. HSA was replaced by $2.5 \mathrm{mg} / \mathrm{mL}$ recombinant albumin (G-MM, Vitrolife), to eliminate the potential effects of contaminants inherent in serum albumin [35-37]. All reagents were obtained from Sigma-Aldrich except for the essential amino acids (minimal essential medium [MEM] Cellgro; Corning Life Sciences, Tewksbury, MA, USA) and hyaluronan ( $0.125 \mathrm{mg} / \mathrm{mL}$, Vitrolife). All chemicals and plastics were tested in a mouse pronucleate oocyte bioassay prior to use [38].

\section{Differential staining}

Blastocyst cell allocation to the inner cell mass (ICM) or trophectoderm (TE) was determined using a differential staining protocol 
$[39,40]$. All procedures were performed at $37^{\circ} \mathrm{C}$. Blastocysts were washed in G-MOPS PLUS between all steps except the last, and all reagents were obtained from Sigma-Aldrich unless specified. Simple G1 medium without non-essential amino acids, alanyl glutamine, taurine, or HSA, containing $4 \mathrm{mg} / \mathrm{mL}$ of polyvinylpyrrolidone was used to dilute 2,4,6-trinitrobenzenesulfonic acid (TNBS) and anti-dinitrophenyl antibody.

Blastocysts were incubated in $0.5 \%$ pronase until the zona was no longer visible, then in $0.5 \%$ TNBS for 10 minutes. Blastocysts were then transferred to $10 \%$ rabbit anti-dinitrophenyl antibody for 10 minutes, and then to guinea pig serum (IMVS, Adelaide, Australia) diluted by $50 \%$ in $0.02 \mathrm{mg} / \mathrm{mL}$ propidium iodide in G-MOPS, until blebbing of the cell membranes was observed. The final step was incubation in $0.1 \mathrm{mg} / \mathrm{mL}$ of bisBenzimide (Hoechst 33258) in G-MOPS and $10 \%$ ethanol for 20 minutes. Blastocysts were then washed briefly and mounted in glycerol on a glass microscope slide. Images were captured on an Eclipse TS100 inverted fluorescent microscope with a DS-Fi1 camera and digital sight control unit (Nikon Instruments). Cells were counted using ImageJ (U.S. National Institutes of Health, Bethesda, MD, USA; http://imagej.nih.gov/ij) with the cell counter plugin. The number of ICM cells divided by the total number of cells per blastocyst was defined as \%ICM.

\section{IL-6 dose response}

Recombinant mouse IL-6 (Life Technologies, Carlsbad, CA, USA) or human IL-6 (R\&D Systems, Minneapolis, MN, USA) was added to both media (G1 and G2) in a dose-response experiment at 0.01, 0.1, 1, 10, and $100 \mathrm{ng} / \mathrm{mL}$. Embryos were stained at 118 hours post-hCG.

\section{Statistical analysis}

All tests were conducted in SPSS ver. 22.0 (IBM Corp., Armonk, NY, USA) and differences were considered statistically significant when $p<0.05$. Percentage data were compared by Yates' corrected chisquare test. Comparison of means was conducted by general linear model univariate analysis with replicate as a random factor. Multiple comparisons were performed with the least significant difference test to compare each treatment with the control.

\section{Results}

\section{Murine IL-6}

The addition of rmlL- 6 had no effect on embryo development on day 3 (Figure $1 \mathrm{~A}$ ). On day $4,10 \mathrm{ng} / \mathrm{mL}$ of rmlL-6 increased the number of embryos that had reached the blastocyst stage compared to the control ( $96 \%$ vs. $81 \%, p=0.01)$, due to an increase in hatching ( $54 \%$ vs. $31 \%, p<0.01$ ) (Supplement 1), but the effect of other doses was not statistically significant. On day 5 , more embryos were hatching or fully hatched when cultured with 0.01 or $10 \mathrm{ng} / \mathrm{mL}$ of rmIL-6 compared to the control ( $93 \%$ and $93 \%$ vs. $78 \%, p<0.05$ ), but the increase in hatching caused by 0.1 or $1 \mathrm{ng} / \mathrm{mL}$ was not statistically significant $(90 \%, p<0.07)$.

Media supplementation with rmlL-6 increased the total number of cells in blastocysts when the dose was $0.1 \mathrm{ng} / \mathrm{mL}$ compared to the control $(101.95 \pm 3.36$ vs. $91.31 \pm 3.33, p<0.05)$ (Figure 1B), whereas the highest dose of $100 \mathrm{ng} / \mathrm{mL}$ decreased the total number of cells $(79.86 \pm 3.29, p<0.05)$. This decrease was also observed in the ICM $(14.45 \pm 1.21$ vs. $17.83 \pm 1.16, p<0.05)$. The $\%$ ICM was decreased by $0.01 \mathrm{ng} / \mathrm{mL}$ of rmlL- 6 but not by any other dose $(15.9 \% \pm 0.9 \%$, $p<0.05)$.

\section{Human IL-6}

There was no effect of recombinant human IL-6 (rhlL-6) on embryo development on days 3-5, except that more embryos reached the expanded blastocyst stage or beyond on day 4 after addition of 1 or
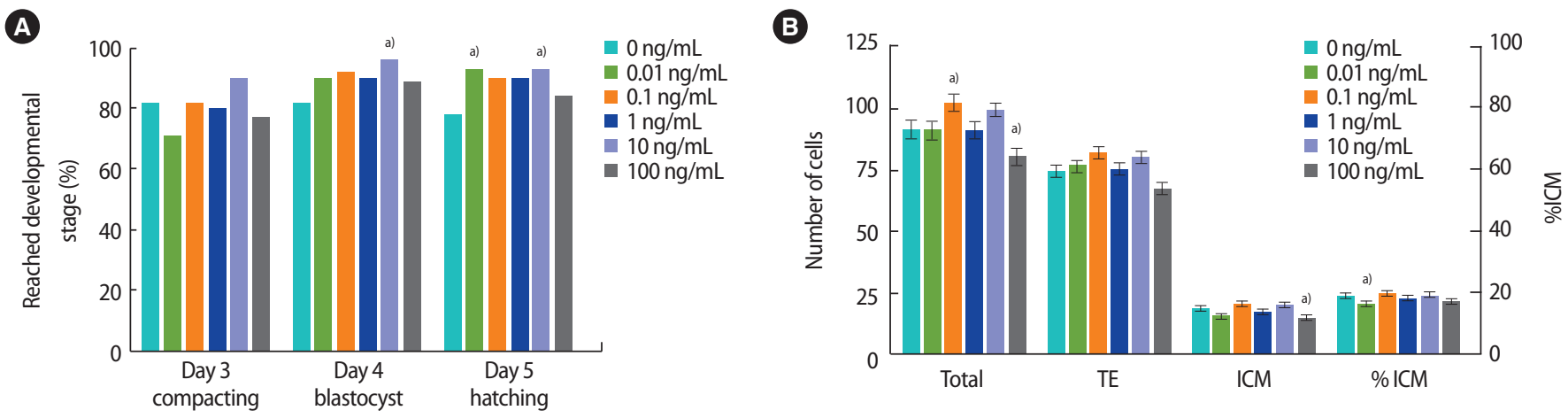

Figure 1. Supplementation of individual mouse embryo culture with recombinant mouse IL-6. (A) Bars represent the proportion of embryos that reached the indicated developmental stage or beyond on each day of culture (70,94, and 118 hours post-hCG). (B) Bars represent cells per blastocyst (mean \pm SEM). Embryos were stained at 118 hours post-hCG. $n=70-73$ per treatment, 5 replicates. TE, trophectoderm; ICM, inner cell mass; IL, interleukin; hCG, human chorionic gonadotropin; SEM, standard error of the mean. ${ }^{\text {a) }} p<0.05$ compared to control. 
A

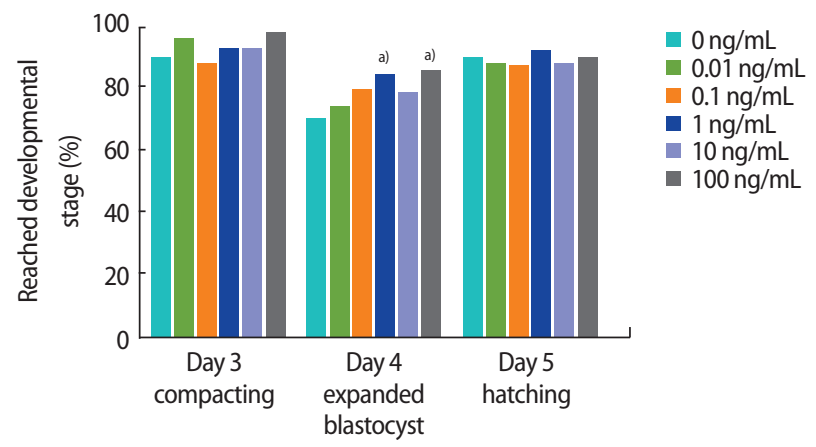

B

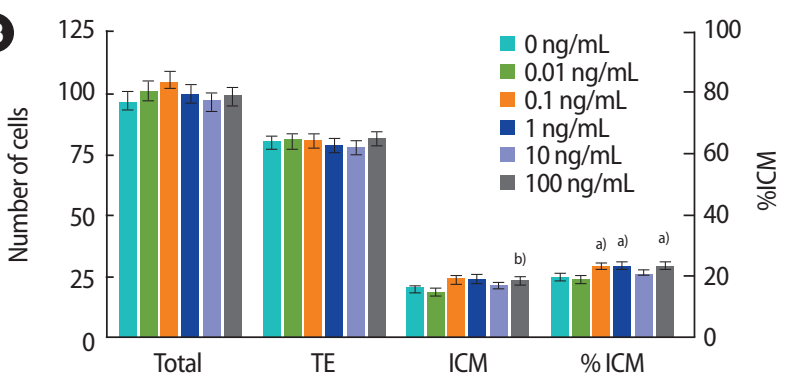

Figure 2. Supplementation of individual mouse embryo cultures with recombinant human IL-6. (A) Bars represent the proportion of embryos that reached the indicated developmental stage or beyond on each day of culture $(70,94$, and 118 hours post-hCG). (B) Bars represent cells per blastocyst (mean \pm SEM). Embryos were stained at 118 hours post-hCG. $n=75-79$ per treatment, 6 replicates. TE, trophectoderm; ICM, inner cell mass; IL, interleukin; $\mathrm{hCG}$, human chorionic gonadotropin; $\mathrm{SEM}$, standard error of the mean. ${ }^{\mathrm{a})} p<0.05$ compared to control; ${ }^{\text {bl }} p=0.051$ compared to control.

$100 \mathrm{ng} / \mathrm{mL}$ compared to the control ( $84 \%$ and $85 \%$ vs. $70 \%, p<0.05$ ) (Figure 2A, Supplement 2).

There was no significant effect of rhlL-6 on the total cell number of blastocysts or the number of TE cells (Figure 2B); however, the number of cells in the ICM was higher when $100 \mathrm{ng} / \mathrm{mL}$ of rhlL- 6 was added to the media compared to the control $(23.0 \pm 1.5$ vs. $19.6 \pm 1.4$, $p=0.051$ ). In addition, the \%ICM was increased by culture with $0.1,1$ or $100 \mathrm{ng} / \mathrm{mL}$ of rhlL-6 $(19.5 \% \pm 1.0 \%$ vs. $22.9 \% \pm 1.1 \%, 23.3 \% \pm 1.1 \%$, $23.1 \% \pm 1.1 \%, p<0.05)$, but not $10 \mathrm{ng} / \mathrm{mL}(20.8 \% \pm 1.1 \%)$.

\section{Discussion}

The lower doses of murine IL-6 appeared to promote the development of mouse embryos. The mean total cell numbers were approximately $12 \%$ higher after supplementation with $0.1 \mathrm{ng} / \mathrm{mL}$ of rmlL-6, but not other doses of rmlL-6. Supplementation between 0.01 and $10 \mathrm{ng} / \mathrm{mL}$ also increased the hatching rate on days 4 and/or 5 . In contrast, the highest dose of $100 \mathrm{ng} / \mathrm{mL}$ of rmlL- 6 reduced total cell numbers by approximately $13 \%$ compared to the control, particularly in the ICM.

These results contrast with those of Shen et al. [25], who reported that supplementation with $100 \mathrm{ng} / \mathrm{mL}$ of rmlL-6 resulted in an increase in blastocyst cell number, TE, and ICM compared to the control. The experiments by Shen et al. were conducted in $20 \%$ oxygen rather than 5\%, and using M16 medium, which lacks amino acids; therefore, the embryos would have been under considerably more stress than in our experiments. The authors did not state whether the embryos were cultured in groups or individually, nor did they specify the media volume used. It is likely that these culture conditions influenced the optimal dose of rmlL-6. Another study by Desai et al. [41] found that $0.5 \mathrm{ng} / \mathrm{mL}$ of IL- 6 increased the hatching rate, and that 1 $\mathrm{ng} / \mathrm{mL}$ increased both the blastocyst rate and hatching rate. The ac- tivity of these lower doses is more consistent with our results for mouse IL-6, possibly because these authors cultured embryos in a-MEM, which contains amino acids, and a plasma protein supplement that may have contained many other active molecules. However, culture was still performed under $20 \%$ oxygen and the authors neither specified if the embryos were cultured in groups or individually, nor indicated the media volume used. Importantly, the authors also did not specify whether mouse or human IL-6 was used.

IL- 6 acts on cells by binding transmembrane IL-6R or soluble IL-6R, which then forms a complex with another transmembrane protein, gp130 (reviewed in [18]). This then triggers a diverse range of possible intracellular signaling cascades. The classic signaling pathway begins with the activation of Janus kinases (JAK) and STAT3, but Srcfamily kinases, PI3K/AKT and Ras/MAPK signaling cascades can also be activated by IL-6. These signaling cascades regulate a wide variety of genes involved in survival, invasion, angiogenesis, differentiation, apoptosis regulation, paracrine signaling, and cell cycle control [18].

These actions of IL- 6 depend on cell type and environment, and little is known about the intracellular pathways activated by IL-6 in in vitro cultured mammalian embryos. Shen et al. [25] found that in mouse blastocysts, exogenous IL- 6 appears to act via the classical pathway (i.e., activation of STAT3), which increases miRNA-21 expression, and consequently upregulates anti-apoptotic Bc|211. Our observation that IL-6 increased cell numbers may be due to this suppression of apoptosis, but some apoptosis is a necessary part of blastocyst development [42], so further investigation is required to determine whether higher cell numbers are indicative of more viable embryos or the survival of abnormal cells.

The possibility that the observed increase in cell number is due to IL-6 stimulating cell proliferation has not yet been investigated. Likewise, it is uncertain whether the changes in lineage determination we observed occurred because of JAK/STAT3 signaling, which influ- 
ences Nanog, Sox2 and Oct3/4 (as observed in porcine blastocysts [32]), or by another mechanism.

Exactly how IL-6 causes the observed increase in blastocyst hatching is also uncertain; it may plausibly be due to the increased number of cells, or there may be a more direct mechanism. Blastocyst hatching in vitro occurs due to pressure from the expanding blastocoel cavity combined with zona-thinning protease secretion $[43,44]$. This protease secretion may be stimulated by growth factors and cytokines [45]; for example, matrix metalloproteinase secretion in blastocyst outgrowths is upregulated by leukemia inhibitory factor (LIF) [46], a member of the IL-6 family. It is likely this occurs through STAT3 signaling [47], and IL-6 may act in a similar way.

Human IL- 6 has only $42 \%$ amino acid sequence homology with mouse IL-6 [30], and has less affinity for the murine receptor than murine IL-6 [31]. Interestingly, the effects of rhIL-6 on mouse embryos were different from the effect of rmlL-6 in this study. No increase in the total cells or hatching rate was observed, and instead rhlL-6 increased the \%ICM. This finding was unexpected, as rhIL- 6 was predicted to have the same effects as rmlL-6, but higher doses would be required. Increased \%ICM is indicative of embryo viability, so there appears to be some cross-species benefit of IL-6, but possibly through a different mechanism than rmIL-6.

These data show that IL- 6 improves the development of individually cultured mouse embryos in optimal culture conditions. However, the mechanism, efficacy, and safety of IL-6 should be thoroughly investigated in animal models before testing on human embryos, including studies on fetal and placental development. IL- 6 joins a long list of cytokines and growth factors that have embryotrophic properties in vitro (reviewed in [12]). Potentially a combination of these could be used to supplement culture media, but understanding the consequences of multiple interactions between these molecules is the challenge we now face.

\section{Conflict of interest}

No potential conflict of interest relevant to this article was reported.

\section{Supplementary materials}

Supplement 1. Addition of recombinant mouse IL-6 to mouse embryo culture. Supplemental data can be found at: http://ecerm.org/ $\mathrm{src} / \mathrm{sm} / \mathrm{cerm}-44-119-\mathrm{s} 001 . p d f$.

Supplement 2. Addition of recombinant human IL-6 to mouse embryo culture. Supplemental data can be found at: http://ecerm.org/ $\mathrm{src} / \mathrm{sm} / \mathrm{cerm}-44-119-\mathrm{s} 002 . p d f$.

\section{References}

1. Christianson MS, Zhao Y, Shoham G, Granot I, Safran A, Khafagy A, et al. Embryo catheter loading and embryo culture techniques: results of a worldwide web-based survey. J Assist Reprod Genet 2014;31:1029-36.

2. Feuer S, Rinaudo P. From embryos to adults: a DOHaD perspective on in vitro fertilization and other assisted reproductive technologies. Healthcare (Basel) 2016;4. pii: E51.

3. Ebner T, Shebl O, Moser M, Mayer RB, Arzt W, Tews G. Group culture of human zygotes is superior to individual culture in terms of blastulation, implantation and life birth. Reprod Biomed Online 2010;21:762-8.

4. Kelley RL, Gardner DK. Combined effects of individual culture and atmospheric oxygen on preimplantation mouse embryos in vitro. Reprod Biomed Online 2016;33:537-49.

5. Paria BC, Dey SK. Preimplantation embryo development in vitro: cooperative interactions among embryos and role of growth factors. Proc Natl Acad Sci U S A 1990;87:4756-60.

6. Lane $M$, Gardner DK. Effect of incubation volume and embryo density on the development and viability of mouse embryos in vitro. Hum Reprod 1992;7:558-62.

7. Keefer CL, Stice SL, Paprocki AM, Golueke P. In vitro culture of bovine IVM-IVF embryos: cooperative interaction among embryos and the role of growth factors. Theriogenology 1994;41: 1323-31.

8. Gardner DK, Lane M, Spitzer A, Batt PA. Enhanced rates of cleavage and development for sheep zygotes cultured to the blastocyst stage in vitro in the absence of serum and somatic cells: amino acids, vitamins, and culturing embryos in groups stimulate development. Biol Reprod 1994;50:390-400.

9. Kelley RL, Gardner DK. In vitro culture of individual mouse preimplantation embryos: the role of embryo density, microwells, oxygen, timing and conditioned media. Reprod Biomed Online 2017;34:441-54.

10. Fujita T, Umeki H, Shimura H, Kugumiya K, Shiga K. Effect of group culture and embryo-culture conditioned medium on development of bovine embryos. J Reprod Dev 2006;52:137-42.

11. Stoddart NR, Wild AE, Fleming TP. Stimulation of development in vitro by platelet-activating factor receptor ligands released by mouse preimplantation embryos. J Reprod Fertil 1996;108:4753.

12. Thouas GA, Dominguez F, Green MP, Vilella F, Simon C, Gardner DK. Soluble ligands and their receptors in human embryo development and implantation. Endocr Rev 2015;36:92-130.

13. Wydooghe E, Vandaele L, Heras S, De Sutter P, Deforce D, Peelman L, et al. Autocrine embryotropins revisited: how do embry- 
os communicate with each other in vitro when cultured in groups? Biol Rev Camb Philos Soc 2017;92:505-20.

14. Austgulen R, Arntzen KJ, Vatten LJ, Kahn J, Sunde A. Detection of cytokines (interleukin-1, interleukin-6, transforming growth factor-beta) and soluble tumour necrosis factor receptors in embryo culture fluids during in-vitro fertilization. Hum Reprod 1995;10:171-6.

15. Murray R, Lee F, Chiu CP. The genes for leukemia inhibitory factor and interleukin- 6 are expressed in mouse blastocysts prior to the onset of hemopoiesis. Mol Cell Biol 1990;10:4953-6.

16. Yu C, Wang L, Li J, Guo C, Guo X, Zhang X, et al. Ovarian stimulation reduces IL-6 release from mouse and human pre-implantation embryos. Am J Reprod Immunol 2012;68:199-204.

17. Zolti M, Ben-Rafael Z, Meirom R, Shemesh M, Bider D, Mashiach S, et al. Cytokine involvement in oocytes and early embryos. Fertil Steril 1991;56:265-72.

18. Schaper F, Rose-John S. Interleukin-6: biology, signaling and strategies of blockade. Cytokine Growth Factor Rev 2015;26:47587.

19. Jasper MJ, Tremellen KP, Robertson SA. Reduced expression of IL-6 and IL-1alpha mRNAs in secretory phase endometrium of women with recurrent miscarriage. J Reprod Immunol 2007;73: 74-84.

20. Tabibzadeh S, Kong QF, Babaknia A, May LT. Progressive rise in the expression of interleukin- 6 in human endometrium during menstrual cycle is initiated during the implantation window. Hum Reprod 1995;10:2793-9.

21. Sierra-Mondragon E, Gomez-Chavez F, Murrieta-Coxca M, Vazquez-Sanchez EA, Martinez-Torres I, Cancino-Diaz ME, et al. Low expression of IL-6 6 and TNF- $a$ correlates with the presence of the nuclear regulators of NF-KB, IKBNS and BCL-3, in the uterus of mice. Mol Immunol 2015;68(2 Pt A):333-40.

22. Sherwin JR, Smith SK, Wilson A, Sharkey AM. Soluble gp130 is up-regulated in the implantation window and shows altered secretion in patients with primary unexplained infertility. J Clin Endocrinol Metab 2002;87:3953-60.

23. Hannan NJ, Paiva P, Meehan KL, Rombauts L, Gardner DK, Salamonsen LA. Analysis of fertility-related soluble mediators in human uterine fluid identifies VEGF as a key regulator of embryo implantation. Endocrinology 2011;152:4948-56.

24. Sharkey AM, Dellow K, Blayney M, Macnamee M, CharnockJones S, Smith SK. Stage-specific expression of cytokine and receptor messenger ribonucleic acids in human preimplantation embryos. Biol Reprod 1995;53:974-81.

25. Shen XH, Han YJ, Zhang DX, Cui XS, Kim NH. A link between the interleukin-6/Stat3 anti-apoptotic pathway and microRNA-21 in preimplantation mouse embryos. Mol Reprod Dev 2009;76:854-
62.

26. Karagenc L, Lane M, Gardner DK. Granulocyte-macrophage colony-stimulating factor stimulates mouse blastocyst inner cell mass development only when media lack human serum albumin. Reprod Biomed Online 2005;10:511-8.

27. Ziebe S, Loft A, Povlsen BB, Erb K, Agerholm I, Aasted M, et al. A randomized clinical trial to evaluate the effect of granulocytemacrophage colony-stimulating factor (GM-CSF) in embryo culture medium for in vitro fertilization. Fertil Steril 2013;99:1600-9.

28. Stilley KS, Lane M, Gardner DK. Heterologous co-culture of bovine embryos with mouse embryos stimulates blastocyst development and differentiation. Theriogenology 2003;59:459.

29. Spindler RE, Crichton EG, Agca Y, Loskutoff N, Critser J, Gardner DK, et al. Improved felid embryo development by group culture is maintained with heterospecific companions. Theriogenology 2006;66:82-92.

30. Van Snick J, Cayphas S, Szikora JP, Renauld JC, Van Roost E, Boon T, et al. CDNA cloning of murine interleukin-HP1: homology with human interleukin 6. Eur J Immunol 1988;18:193-7.

31. Coulie PG, Stevens M, Van Snick J. High- and low-affinity receptors for murine interleukin 6: distinct distribution on B and T cells. Eur J Immunol 1989;19:2107-14.

32. Shen XH, Cui XS, Lee SH, Kim NH. Interleukin-6 enhances porcine parthenote development in vitro, through the IL-6/Stat3 signaling pathway. J Reprod Dev 2012;58:453-60.

33. Gardner DK, Lane M. Embryo culture systems. In: Gardner DK, editor. In vitro fertilization: a practical approach. New York: Informa Healthcare; 2007. p. 221-82.

34. Gardner DK, Lane M. Mammalian preimplantation embryo culture. Methods Mol Biol 2014;1092:167-82.

35. Bar-Or D, Bar-Or R, Rael LT, Gardner DK, Slone DS, Craun ML. Heterogeneity and oxidation status of commercial human albumin preparations in clinical use. Crit Care Med 2005;33:1638-41.

36. Dyrlund TF, Kirkegaard K, Poulsen ET, Sanggaard KW, Hindkjaer JJ, Kjems J, et al. Unconditioned commercial embryo culture media contain a large variety of non-declared proteins: a comprehensive proteomics analysis. Hum Reprod 2014;29:2421-30.

37. Morbeck DE, Paczkowski M, Fredrickson JR, Krisher RL, Hoff HS, Baumann NA, et al. Composition of protein supplements used for human embryo culture. J Assist Reprod Genet 2014;31:170311.

38. Gardner DK, Reed L, Linck D, Sheehan C, Lane M. Quality control in human in vitro fertilization. Semin Reprod Med 2005;23:31924.

39. Hardy K, Handyside AH, Winston RM. The human blastocyst: cell number, death and allocation during late preimplantation development in vitro. Development 1989;107:597-604. 
40. Thouas GA, Korfiatis NA, French AJ, Jones GM, Trounson AO. Simplified technique for differential staining of inner cell mass and trophectoderm cells of mouse and bovine blastocysts. Reprod Biomed Online 2001;3:25-9.

41. Desai N, Scarrow M, Lawson J, Kinzer D, Goldfarb J. Evaluation of the effect of interleukin- 6 and human extracellullar matrix on embryonic development. Hum Reprod 1999;14:1588-92.

42. Brison DR, Schultz RM. Apoptosis during mouse blastocyst formation: evidence for a role for survival factors including transforming growth factor alpha. Biol Reprod 1997;56:1088-96.

43. Perona RM, Wassarman PM. Mouse blastocysts hatch in vitro by using a trypsin-like proteinase associated with cells of mural trophectoderm. Dev Biol 1986;114:42-52.

44. Ichikawa S, Shibata T, Takehara Y, Tamada H, Oda K, Murao S. Ef- fects of proteinase inhibitors on preimplantation embryos in the rat. J Reprod Fertil 1985;73:385-90.

45. Seshagiri PB, Vani V, Madhulika P. Cytokines and blastocyst hatching. Am J Reprod Immunol 2016;75:208-17.

46. Harvey MB, Leco KJ, Arcellana-Panlilio MY, Zhang X, Edwards DR, Schultz GA. Proteinase expression in early mouse embryos is regulated by leukaemia inhibitory factor and epidermal growth factor. Development 1995;121:1005-14.

47. Wang XH, Liu BR, Qu B, Xing H, Gao SL, Yin JM, et al. Silencing STAT3 may inhibit cell growth through regulating signaling pathway, telomerase, cell cycle, apoptosis and angiogenesis in hepatocellular carcinoma: potential uses for gene therapy. Neoplasma 2011;58:158-71. 